\title{
Health Insurance in India: Rajiv Aarogyasri Health Insurance Scheme in Andhra Pradesh
}

\author{
J. Yellaiah \\ ICSSR Doctoral Fellow, Centre for Economic And Social Studies (CESS), Department of Economics, Osmania \\ University, Hyderabad, Andhra Pradesh.
}

\begin{abstract}
Health insurance as a tool to finance healthcare has very recently gained popularity in India. Government has been putting serious efforts to introduce health insurance for the poor in recent years in order to improve access of poor to quality medical care and for providing financial protection against high medical expenses. There have been several attempts to introduce similar schemes in other states but Andhra Pradesh has been one of the only states to successfully roll out the scheme. The Insurance scheme covered 198.25 lack families out of total across 229.11 Lack families (87\% families covered) residing in 27138 villages 1128 mandals of all districts of the State in five Phases. The scheme started with 330 procedures covered and has been gradually extended to 938 procedures. The majority of beneficiaries utilizing the scheme are illiterate and have a rural address. Since inception of the scheme (01.04.2007) till 18th January 2013- 35713 Medical camps were held by the network hospitals in rural areas. Total Surgeries/Therapies done by under this scheme is 1753466, Government is 440655 and Private is 1312811.
\end{abstract}

Key words: Health Insurance, Aarogyasri Health insurance scheme, Community Health insurance, Healthcare, Healthcare Expenditure.

\section{Introduction:}

Health is an important constituent of human resource development. Good health is real wealth of society. It not only increases human efficiency but also decreases private and public expenditure on sickness and diseases. Health has been declared as a fundamental human right. Healthcare services help to reduce infant mortality rate, check crude death rate, keep diseases under control and raise life expectancy. World development report 1993 stated, "Improved health contributes to economic growth in four ways: It reduces production losses caused by worker illness, it permits the use of natural resources that had been totally or nearly increasable because of disease, it increases the enrolment of children in schools and makes them better able to learn, and it frees for alternative uses resources that would otherwise have to be spent on treating illness. The economic gains are relatively greater for poor people, who are typically most handicapped by ill health and who stand to gain the most from the development of underutilized resources."

Various studies examine effect of Out-Of-Pocket (OOP) health expenditure on poverty head count and whether such expenses push households deeper into poverty. Adversities related to out-of-pocket spending are apparent in the form of intensified poverty and ill fare in the country. For instance, in 1995-96 an estimated $2.2 \%$ of the Indian population fell into poverty because of out-of-pocket spending (Peters et al 2002) and it increased to around 3.2\% in 1999-2000 (Garg and Karan 2009). A significant proportion of population may have had to sell their assets (productive) for inpatient care (Peters et al. 2002; Dilip and Duggal 2002). A significant proportion of population may have had to forgo treatment all together due to scarcity financial resources (NSSO, 60th Round, 2004).

Health insurance can provide financial protection to households in the event of health shock and can reduce catastrophic out-of-pocket expenditure on health care (Joglekar, 2009). So that it can protect families from impoverishment and empower the patient to seek health care as a right (Gilson, 1998).

In developing and low income countries Health care finance is still predominantly based on out-ofpocket (OOP) payments, and the lack of prepayment mechanisms like insurance. In the absence of insurance, an illness not only reduces welfare directly, it also increases the risk of impoverishment due to high treatment expenditures (Wagstaff, A and E. van Doorslaer, 2003).

\section{Objectives of the study:}

1. To discuss the coverage and features of major health insurance schemes in India.

2. To examine the role of A.P state health insurance scheme (Rajeev Aarogya Sri) in Andhra Pradesh. 


\section{Methodology:}

The data collected from secondary sources such as scheme website, available assessment reports, and the data provided by the Aarogya sri health care trust, Scheme website and published articles.

\section{Health Insurance Coverage in India}

The current trends in the health insurance coverage indicate a quantum leap, especially since the last three years, mainly because of the implementation of the health insurance schemes such as Rashtriya Swasthya Bima Yojana (2008), Rajiv Arogyasri scheme (2007), Kalingar (2009) and Vajapayee Arogyasri scheme (2009). In India, in the year 2009-10 all forms of insurance both Government and non-government together covered approximately 302 million individuals or 25 percent of India's population in 2010 (Table 1). And of this nearly 82 percent are covered by government schemes.

Table 1: Scheme-wise Health Insurance Coverage

\begin{tabular}{|c|c|c|c|c|c|c|c|}
\hline \multirow[b]{2}{*}{$\begin{array}{l}\text { Sl. } \\
\text { No }\end{array}$} & \multirow[b]{2}{*}{ Scheme } & \multicolumn{6}{|c|}{ Total covered population in 2009-10 (in millions) } \\
\hline & & $\begin{array}{l}\text { Covering } \\
\text { Group }\end{array}$ & $\begin{array}{c}\text { Unit of } \\
\text { Enrolment }\end{array}$ & $\begin{array}{l}\text { No. of } \\
\text { Families }\end{array}$ & $\begin{array}{c}\text { No. of } \\
\text { beneficiaries }\end{array}$ & $\begin{array}{c}\text { Percentage } \\
\text { of Total } \\
\text { (GSS) }\end{array}$ & $\begin{array}{c}\text { Percentage } \\
\text { of Total }\end{array}$ \\
\hline 1 & CGHS (1954) & $\begin{array}{l}\text { Central Govt. } \\
\text { Employees }\end{array}$ & Family & 0.87 & 3.0 & 1.21 & 0.99 \\
\hline 2 & ESIS (1952) & $\begin{array}{c}\text { All the } \\
\text { Employees }\end{array}$ & Family & 14.3 & 55.4 & 22.4 & 18.34 \\
\hline 3 & $\begin{array}{l}\text { Rashtriya } \\
\text { Swasthya } \\
\text { Bima Yojana } \\
\text { (2008) }\end{array}$ & BPL families & Family & 22.7 & $79.45^{1}$ & 32.1 & 26.3 \\
\hline 4 & $\begin{array}{l}\text { Rajiv } \\
\text { Arogyasri } \\
\text { scheme.AP } \\
\text { (2007) }\end{array}$ & BPL families & Family & 22.4 & 70 & 28.34 & 23.17 \\
\hline 5 & $\begin{array}{l}\text { Kalaignar } \\
\text { (TN) (2009) }\end{array}$ & BPL families & Family & 13.6 & 35 & 14.17 & 11.58 \\
\hline 6 & $\begin{array}{l}\text { Vajapayee } \\
\text { Arogyasri } \\
\text { scheme }(\mathrm{KN}) \\
(2009)\end{array}$ & BPL families & Family & 0.95 & 1.4 & 0.56 & 0.46 \\
\hline 7 & $\begin{array}{l}\text { Yeshasvini } \\
(\mathrm{KN})(2003)\end{array}$ & APL \& BPL & Individual & N/A & 3.0 & 1.21 & 0.99 \\
\hline \multicolumn{5}{|c|}{ Total Government Sponsored Schemes (GSS) } & 247 & 100 & 81.78 \\
\hline 8 & $\begin{array}{l}\text { Private } \\
\text { Health } \\
\text { insurance }\end{array}$ & Voluntary & Individual & N/A & 55 & & 18.21 \\
\hline \multicolumn{5}{|c|}{ Grand Total } & 302 & & 100 \\
\hline
\end{tabular}

It may be observed that a substantial portion is covered (32\%) through Rashtriya Swasthya Bima Yojana (RSBY), followed by the state of Andhra Pradesh with has covered $28.34 \%$ of the total beneficiaries through Rajiv Aarogyasri scheme. And Tamil Nadu (Kalaignar) health insurance covers 14.17\% of population. These are two states where state sponsored health insurance schemes are strongest in their outreach. Private health insurance schemes are covering $18.21 \%$ population.

\section{Key Design Features of Government Sponsored Health Insurance Schemes}

A useful framework to discuss the characteristics of insurance schemes is through the lens of three key functions namely revenue collection, risk pooling and purchasing. The source of funds, mechanisms used to collect funds and the agency that pools funds together are collectively referred to as the 'Revenue collection' function. While, 'pooling of funds' refers to the accumulation and management of funds to ensure that financial risk of having to pay for health care is borne by all and not by individuals who fall ill. The third function is 'Purchasing Care' which refers to paying for health care. In health insurance the insurer or the organizer of the scheme purchases services on behalf of a population. It broadly involves contracting with providers of care, 
designing an appropriate benefit package and making choices around paying for them (McIntyre, 2007). 'Provision of care' is generally separated from purchasing in health insurance and is an integral part of it.

\section{Rajiv Aarogyasri Health Insurance Scheme Of Andhra Pradesh}

Financing health care of persons living below poverty line, especially for the treatment of serious ailments such as cancer, kidney failure, heart diseases, is one of the key determinants that affect the poverty levels in Andhra Pradesh. Indebtedness due to hospital expenditures is one of the main reasons for people falling into poverty in the state. Available network of government hospitals do not have the requisite equipment or the facility or the specialist pool of doctors to meet the state wide requirement for the treatment of such diseases. Large proportions of people, especially below poverty line borrow money or sell assets to pay for hospitalization. Presently many people suffering from such diseases are approaching the Government to provide financial assistance to meet hospitalization expenses for surgical procedures. Hence, there is a felt need in the state to provide medical assistance to families living below poverty line for the treatment of serious ailments such as cancer, kidney failure, heart and neurosurgical diseases etc., requiring hospitalization and surgery/therapy. During the period from 14.05.2004 to 26.06.2007, financial assistance to a tune of Rs. 168.52 crores has been provided from Chief Minister's Relief Fund in 55361 cases to meet hospitalization expenses for such people. From the experience gained, it is felt that the assistance could be institutionalized so that its benefit can be accessed by poor people across the State easily and in a trouble free manner. Therefore, Government of Andhra Pradesh has launched Rajiv Aarogyasri Health Insurance Scheme on 01.04.2007 to improve access of poor to quality medical care and for providing financial protection against high medical expenses.

In order to operate the scheme professionally in a cost effective manner, public private partnership is promoted between the insurance company, the private sector hospitals and the state agencies. Aarogyasri Health Care Trust recently set up by the State Government for the implementation of the scheme assisting the insurance company/ Beneficiaries and co-ordinate with Medical and Health Department, District Collectors, Civil Supplies Department etc.

\section{Objective of the Scheme}

According to PK Agarwal, Principle Secretary at the Department of Health, Medical and Family Welfare, Andhra Pradesh the objective of the Rajiv Aarogyasri Health Insurance scheme is "social protection, addressing healthcare problems that cause indebtedness and often bring people into devastating financial and physical distress." To improve access of BPL families to quality medical care for treatment of identified diseases involving hospitalization, surgeries and therapies, through an identified network of health care providers.

\section{Eligibility}

All below poverty line residents of the state of Andhra Pradesh are technically entitled to Aarogyasri benefits. The scheme has been implemented in all districts in the state. The state already had a mechanism for defining, identifying, and enrolling below poverty line families. Each eligible family is issued a "White Card" (a ration card) to identify them as below poverty line. Aarogyasri uses the "White Card" as a targeting mechanism for its scheme. Such of the beneficiaries who are covered for the "listed therapies" by other insurance schemes such as CGHS, ESIS, Railways, RTC etc., will not be eligible for any benefit under this scheme.

\section{Funding}

This is a state government scheme. Under this, hospital bills of the insured persons are paid by the insurance company. The premium for insurance company is paid by the government. People do not have to pay anything under this scheme. The state wanted to ensure that the benefits of the scheme reached the poorest, who might otherwise be deterred from enrolling even if the premium to be paid out-of-pocket was nominal.

For rollout of Aarogyasri, the State government engaged in an open, competitive bidding process to select a single insurer to implement the program. The insurer with the lowest premium bid (for the specified benefits package) won the contract to be the insurer (Star Health and Allied Insurance Company) for Aarogyasri. For the first phase of Aarogyasri, the premium was set at Rs.210 (US\$4.50) per household annually. The coverage amount for the services to the beneficiaries is upto Rs.1.50 lakh per family per annum. The premium is the same across all districts in the state and the amount reimbursed per procedure to any network hospital is also the same.

\section{Institutional structure}

Rajiv Aarogyasri Trust under the Government of Andhra Pradesh has an overall responsibility of implementing the scheme in the state. The administrative structure of Aarogyasri is comprised of four main organizations: 
Aarogyasri Healthcare Trust: The Trust is responsible for oversight of the entire insurance program as well as some important administrative functions such as setting benefits and pricing, managing contracts with insurer (s) and network providers, approving claims, and monitoring.

Insurer: The insurer is selected based on a competitive bidding process to bear risk and manage all back end insurance administration, including claims processing, reimbursements to providers, and oversight of hospitals. The Insurer is also responsible for holding health camps in villages to screen, diagnose, treat, and make beneficiaries aware of any health problems they might have; health camps are also used to enrol eligible beneficiaries.

Network hospitals: Network hospitals provide care to Aarogyasri beneficiaries.

Aarogya Mithras: Aarogya Mithras are patient advocates and assist Aarogyasri beneficiaries to navigate through the system and ensure beneficiaries receive quality care. Aarogya Mithras are also responsible for community outreach.

Figure 1: Institutional Structure of Rajiv Aarogyasri Health Insurance Scheme

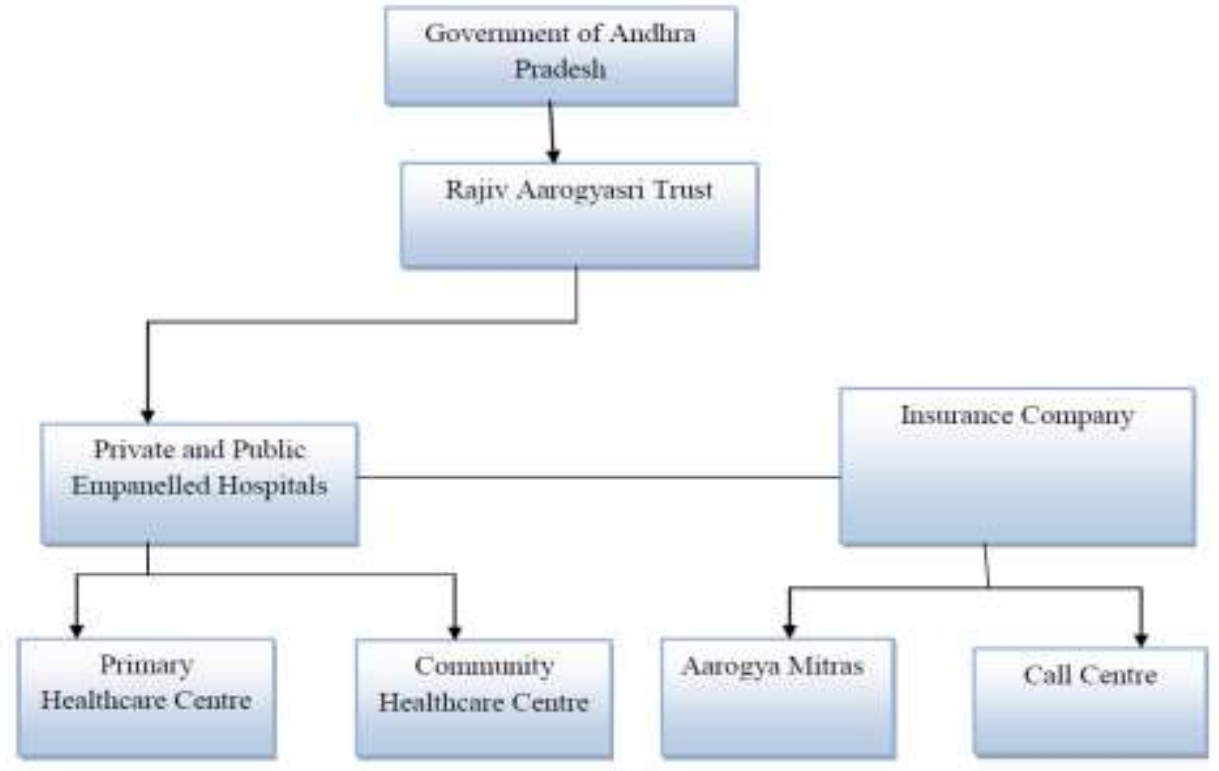

STAR Health Insurance Company is responsible for enrolment, empanelment of hospitals, processing claims and monitoring of the scheme. STAR is also responsible for recruitment of Arogyamithra's, field level first contact person for the beneficiaries responsible for facilitating access to health care services. STAR is also responsible for managing call centres, and for facilitating access to health care services by beneficiaries. Aarogyasri Trust also empanels hospitals, mainly public health care hospital and few private health care hospitals. They are also responsible for ensuring facilitation of health care access of beneficiaries whose primary contact points are primary health care centres or community health care centres.

\section{Scheme Coverage:}

Population Cover: Population Cover during the 2011-12 year, Rajiv Aarogyasri Health Insurance scheme was extended to the entire state in 5 Phases.

\begin{tabular}{|l|l|l|l|l|l|}
\hline \multicolumn{7}{|c|}{ Table 2: Phase wise districts } \\
\hline Phase 1 & Mahboobnagar & Srikakulam & Anantapur & & \\
\hline Phase 2 & Rangareddy & Nalgonda & Chittoor & West Godavari & East Godavari \\
\hline Phase 3 & Medak & Karimnagar & Prakasam & Kadapa & Nellore \\
\hline Phase 4 & Adilabad & Kurnool & Hyderabad & Visakhapatnam & Vijayanagaram \\
\hline Phase 5 & Nizamabad & Warangal & Khammam & Guntur & Krishna \\
\hline
\end{tabular}

Source: Annual report of Aarogyasri Health Insurance scheme 2011-12 
Health Insurance In India: Rajiv Aarogyasri Health Insurance Scheme In Andhra Pradesh

\begin{tabular}{|c|l|l|l|l|l|}
\hline \multicolumn{7}{|c|}{ Table 3: Phase wise Coverage under Insurance } \\
\hline Phase & \multicolumn{1}{|c|}{ Period } & $\begin{array}{c}\text { Total Families } \\
\text { (In lacs) }\end{array}$ & $\begin{array}{c}\text { BPL Families } \\
\text { (In lacs) }\end{array}$ & $\begin{array}{c}\text { No. of } \\
\text { Procedures }\end{array}$ & $\begin{array}{c}\text { Premium } \\
\text { (Rs) } \\
\text { Per Family }\end{array}$ \\
\hline Phase 1 & $5-4-11$ to 4-4-12 & 31.12 & 26.67 & 938 & $489 /-$ \\
\hline Phase 2 & $5-12-10$ to4-12-11 & 56.09 & 49.49 & 938 & $531.99 /-$ \\
\hline Phase 3 & $15-4-11$ to 14-4-12 & 44.30 & 38.44 & 938 & $489 /-$ \\
\hline Phase 4 & $17-7-11$ to 16-7-12 & 44.56 & 38.19 & 192 & $279 /-$ \\
\hline Phase 5 & $17-7-11$ to 16-7-12 & 53.04 & 45.46 & 192 & $279 /-$ \\
\hline & & $\mathbf{2 2 9 . 1 1}$ & $\mathbf{1 9 8 . 2 5}$ & & \\
\hline
\end{tabular}

Source: Annual report of Aarogyasri Health Insurance scheme 2011-12

The Insurance scheme covered 198.25 lack families out of total across 229.11 Lack families (87\% families covered) residing in 27138 villages 1128 mandals of all districts of the State in five Phases. A poor family having a white ration card becomes eligible for the scheme. The beneficiary is identified and authenticated through the online database of the Civil Supplies department of Government of Andhra Pradesh. There is no limit on the size of the family. Andhra Pradesh has the advantage of photo ration cards issued to all eligible BPL families by Civil Supplies Department. Taking advantage of this unique fool proof facility, BPL ration cards issued by Civil Supplies Department with family details and photograph were taken as the eligibility card for the scheme. The authentication under the scheme is done through a white ration card.

\begin{tabular}{|l|c|c|c|c|c|c|}
\hline \multicolumn{7}{|c|}{ Table 4: Phase wise cards and population } \\
\hline PHASE & 1 & 2 & 3 & 4 & 5 & Total \\
\hline $\begin{array}{l}\text { Cards(in } \\
\text { Lakhs) }\end{array}$ & 26.68 & 57.33 & 38.45 & 38.19 & 45.46 & 206.11 \\
\hline $\begin{array}{l}\text { Population } \\
\text { (in lakhs) }\end{array}$ & 93.35 & 200.66 & 132.91 & 133.67 & 159.12 & 719.71 \\
\hline
\end{tabular}

Source: Annual report of Aarogyasri Health Insurance scheme 2011-12

This shows that $86 \%$ of the families of the State are BPL. This figure is at large variance with that given by Government of India which is in the range of $40 \%$. It is believed that Aarogyasri Scheme has fuelled the demand for possessing a BPL card. This cause along with the Government of Andhra Pradesh BPL line fixation at Rs.60000 in rural areas and Rs.75000 in urban areas could explain the reason for a high number of BPL families in the state.

\section{Benefit Coverage:}

The scheme covers 932 therapies in 29 specialties such as cancer, cardiology, poly trauma etc. There are 380 network hospitals serving the patients. The benefit coverage under the scheme increased from 166 procedures to 884 procedures.

\section{Performance of the Scheme:}

M. Rao. et. al ( 2011), the Rajiv Aarogyasri Community Health Insurance Scheme (RACHIS) impact of this scheme was evaluated by a rapid assessment, commissioned by the government of Andhra Pradesh. The aim of the assessment was to explore the contribution of the scheme to the reduction of catastrophic health expenditure among the poor and to recommend ways by which delivery of the scheme could be improved. This novel scheme was beginning to reach the BPL households in the state and providing access to free secondary and tertiary healthcare to seriously ill poor people. An integrated model encompassing primary, secondary and tertiary care would be of greater benefit to families below the poverty line and more cost-effective for the government. There is considerable potential for the government to build on this successful start and to strengthen equity of access and the quality of care provided by the scheme.

Table- 5 Vital statistics of Aarogyasri Health Insurance Scheme as on $18^{\text {th }}$ January, 2013

\begin{tabular}{|l|r|l|}
\hline \multicolumn{1}{|c|}{ Vital statistics } & \multicolumn{1}{c|}{ Since April 1st 2007 } \\
\hline Health Camps & & 35713 \\
\hline \multirow{3}{*}{ Preauthorizations } & Government & 501799 \\
\cline { 2 - 3 } & Private & 1411335 \\
\cline { 2 - 3 } & Total & 1766119 \\
\hline
\end{tabular}


Health Insurance In India: Rajiv Aarogyasri Health Insurance Scheme In Andhra Pradesh

\begin{tabular}{|l|r|l|}
\hline \multirow{4}{*}{ Out Patients } & Government & 527390 \\
\cline { 2 - 3 } In Patients & Private & 3644189 \\
\cline { 2 - 3 } & Total & 4232829 \\
\hline \multirow{3}{*}{ Patients } & Government & 534017 \\
\cline { 2 - 3 } & Private & 1425622 \\
\hline \multirow{3}{*}{ Surgeries/Therapies } & Total & 1959655 \\
\cline { 2 - 3 } & Screened & 6575227 \\
\hline \multirow{3}{*}{ Amount Preauthorized } & Registered & 6539949 \\
\cline { 2 - 3 } & Government & 440655 \\
\cline { 2 - 3 } & Private & 1312811 \\
\cline { 2 - 3 } & Total & 1753466 \\
\cline { 2 - 3 } & Government & Rs. $1071 \mathrm{Cr}$ \\
\hline
\end{tabular}

Source: www.aarogyasri.org.

Table 5 shows about Vital statistics of Aarogyasri Health Insurance Scheme as on 18th January, 2013. Since inception of the scheme (01.04.2007) till 18th January 2013- 35713 Medical camps were held by the network hospitals in rural areas. Total Surgeries/Therapies done by under this scheme is 1753466 , Government is 440655 and Private is 1312811. Total Patients Screened under the scheme is 6575227 and Patients Registered under the scheme is 6539949. Total Out Patients 4232829, Government 527390, and Private 3644189 and In Patients Total 1959655, Government 534017, and Private 1425622.

Total Number of therapies preauthourized under Aarogyasri scheme is 1766119, Government 501799 and Private 1411335. Total Amount Preauthorized under this scheme is Rs.4723 Cr, Government Rs.1071 Cr and Private Rs.3652 Cr.

Table 6: District - wise Total Number of therapies preauthourized under Aarogyasri

\begin{tabular}{|c|l|l|c|}
\hline Sl. No & District Name & $\begin{array}{c}\text { No. of therapies } \\
\text { preauthourized }\end{array}$ & Percentage \\
\hline 1 & Hyderabad & 506896 & 28.70 \\
\hline 2 & Adilabad & 2156 & 0.12 \\
\hline 3 & Anantpur & 17875 & 1.01 \\
\hline 4 & Chittoor & 77302 & 4.37 \\
\hline 5 & East Godavari & 134251 & 7.60 \\
\hline 6 & Guntur & 145365 & 8.23 \\
\hline 7 & YSR Kadapa & 10616 & 0.60 \\
\hline 8 & Khammam & 16838 & 0.95 \\
\hline 9 & Kurnool & 66359 & 3.75 \\
\hline 10 & Krishna & 152545 & 8.63 \\
\hline 11 & Karimnagar & 61104 & 3.45 \\
\hline 12 & Mahboobnagar & 11362 & 0.64 \\
\hline 13 & Medak & 2357 & 0.13 \\
\hline 14 & Nalgonda & 7824 & 0.44 \\
\hline 15 & Nellore & 97306 & 5.50 \\
\hline 16 & Nizamabad & 14029 & 0.79 \\
\hline 17 & Prakasham & 15372 & 0.87 \\
\hline 18 & Ranga Reddy & 113296 & 6.41 \\
\hline 19 & Srikakulam & 13929 & 0.78 \\
\hline & & & \\
\hline
\end{tabular}


Health Insurance In India: Rajiv Aarogyasri Health Insurance Scheme In Andhra Pradesh

\begin{tabular}{|l|l|l|l|}
\hline 20 & Visakhapatnam & 151796 & 8.59 \\
\hline 21 & Vizianagaram & 20643 & 1.16 \\
\hline 22 & Warangal & 75066 & 4.25 \\
\hline 23 & West Godavari & 51832 & 2.93 \\
\hline & Total & 1766119 & 99.9 \\
\hline
\end{tabular}

Source: www.aarogyasri.org

Table 6 shows about District wise Total Number of therapies preauthourized under Aarogyasri scheme. It has been found that the total number of therapies preauthourized that have been taken under this scheme is 1766119 . Highest number of therapies preauthourized in Hyderabad district 28.70 percent (506896), Krishna district 8.63 percent (152545) and Visakhapatnam district 8.59 percent (151796). Lowest number of therapies preauthourized in Adilabad district 0.12 percent (2156) and Medak district 0.13 percent (2357).

\section{Conclusion:}

The state of Andhra Pradesh in India established the Rajiv Aarogyasri Community Health Insurance Scheme (RACHIS) in 2007 with the aim of breaking this cycle by improving the access of below the poverty line (BPL) families to secondary and tertiary healthcare. It covered a wide range of surgical and medical treatments for serious illnesses requiring specialist healthcare resources not always available at district-level government hospitals. The Insurance scheme covered 198.25 lack families out of total across229.11 Lack families (87\% families covered) residing in 27138 villages 1128 mandals of all districts of the State in five Phases. The scheme started with 330 procedures covered and has been gradually extended to 938 procedures. The majority of beneficiaries utilizing the scheme are illiterate and have a rural address. Since inception of the scheme (01.04.2007) till 18th January 2013- 35713 Medical camps were held by the network hospitals in rural areas. Total Surgeries/Therapies done by under this scheme is 1753466, Government is 440655 and Private is 1312811. Total Patients Screened under the scheme is 6575227 and Patients Registered under the scheme is 6539949. Total Number of therapies preauthourized under Aarogyasri scheme is 1766119, Government 501799 and Private 1411335. Total Amount Preauthorized under this scheme is Rs. 4723 Cr, Government Rs.1071 Cr and Private Rs.3652 Cr.

The Aarogyasri Health Insurance Scheme is giving more protection to the poor people. And the can access Government hospital or Private hospital which they required for treatment. Most of the people were giving priority to the private/ corporate hospitals in urban areas of the Andhra Pradesh. N. Purendra Prasad and P. Raghavendra (2012), the scheme is only the construction of a new system that supplants the severely underfunded state healthcare system. It is also a classic example of promoting the interests of the corporate health industry through tertiary hospitals in the public and private sectors.

\section{Remarks of the Scheme}

The priorities of this scheme have been criticized in India and internationally. The main criticism has been about the benefit package that focuses on alleviating the financial distress associated with catastrophic illness and ignores health problems faced by the majority of the poor such as fever and gastrointestinal disorders. The two main reasons for the chosen focus of Aarogyasri are: (1) the purpose of addressing indebtedness due to health care costs; and (2) the challenges with monitoring treatment of ailments without hospitalization.

Shukla, et al., (2011) they pointed out that, corporate hospitals handle the biggest share of the cases and there is no provision for outpatient treatment of everyday illnesses that affect the working capacity of the patient. The focus on tertiary healthcare and exclusion of all other forms of medical assistance leads to an inefficient medical care model with a low level of real impact on meeting the needs of the healthcare and the health of the population. Mitchell et al., (2011) in their study provide evidence that poor patients continue to spend significantly on conditions that are not covered by the Rajiv Aarogya Sri (RAS) at both government and private facilities. Their findings show that RAS alone is not likely to reduce the financial burden of illness on the BPL population. They suggested that strong referral system and fundamental changes to the health system are needed to meet goals of financial risk protection.

\section{References:}

[1] Aarogyasri Healthcare Trust (2010): Rajiv Aarogyasri Health Insurance Scheme Brochure.

[2] Annual Report of Aarogyasri health insurance scheme 2011-12, PP 11-13.

[3] Dilip, T.R., and Duggal, R., (2002): Incidence of non-fatal Health Outcomes and Debt in Urban India, Draft paper presented for urban research symposium, 9-11 December 2002, at World Bank, Washington D.C.

[4] Dror, and D.M.Jacquier(1999): Micro-insurance: Extending health insurance to the excluded , International Social Security Review, 52(1):71-97.

[5] Ellies, R.P, Monner Alam and Indrani Gupta (2000): Health insurance in India: Prognosis and Prospects, Economic and Political Weekly, 35(4). 
[6] Garg C. C and Anup A.K. (2009): Reducing out-of-pocket Expenditures to Reduce Poverty: A Disaggregate Analysis at Rural Urban and State Level in India, Health Policy and Planning, 24: 116-128.

[7] Geoffrey D Paulin and Elizabeth M Dietz (1995): Health Insurance Coverage for Families with Children, Monthly Labour Review, August: 13-23.

[8] Gilson, L (1998): In Defence and Pursuit of Equity, Social Science Medicine, 47(12):1891-1896.

[9] Mitchel, A, Mahal, A and Bossert, T (2011): "Healthcare Utilisation in Rural Andhra Pradesh", Economic and Political Weekly, 46(5):15-19.

[10] M. Rao. Et. Al ( 2011), "Addressing healthcare needs of people living below the poverty line: a rapid assessment of the Andhra Pradesh health insurance scheme", The National Medical Journal of India, vol. 24, no. 6, 2011, pp. 335-341.

[11] McIntyre, D (2007), "Learning from Experience: Health care financing in low-and middle income countries", Global Forum for Health Research, Geneva, 2 940286-53-1.

[12] N. Purendra Prasad and P. Raghavendra (2012), "Healthcare Models in the Era of Medical Neo-liberalism A Study of Aarogyasri in Andhra Pradesh", Economic and Political Weekly, October 27, 2012, VOL. XLVII NO 43. Pp. 118-126

[13] Public Health Foundation of India (2011)," A Critical Assessment of the Existing Health Insurance Models in India", Report of Working Group, Submitted to Planning Commission of India.

[14] Peters, D., Yazbeck, A.S., Sharma R., Ramana, G.N.V., Pritchett, L, Wagstaff, A. (2002): Better Health Systems for India's Poor. Findings, Analysis and Options, Washington DC:World Bank.

[15] Shukla, R, Shatrugna, V and Srivatsan, R (2011): “Aarogyasri Healthcare Model: Advantage Private Sector", Economic and Political Weekly, 46(49):38-42.

[16] Wagstaff,A and E.van Doorslaer (2003): Catastrophe and Impoverishment in Paying for Health Care: With Applications to Vietnam 1993-98, Health Economics, 12: 921-934.

[17] www.aarogyasri.org

[18] http://esic.nic.in/

[19] http://iib.gov.in/IRDA/healthpub/Health\%20Report_0809.pdf

[20] http://mohfw.nic.in/cghsnew/index.asp 